\title{
Dante y los Padres de la
}

\section{Iglesia. Aspectos Generales}

\section{y Particulares}

Giancarlo Bellina Shols*

Instituto Superior de Estudios Teológicos Juan XXIII gcbellina@hotmail.com

Resumen: En sus obras, Dante revela una formación intelectual en la que es considerable la presencia e influencia de la historia y de la producción cultural del cristianismo tardoantiguo, adquirida por medio del estudio tanto de obras de sus coetáneos como de los mismos textos patrísticos. En estas páginas se exponen algunos aspectos generales (2) y particulares (3) de su formación y producción con el fin de mostrar de qué manera el Padre de la lengua italiana estima y utiliza modelos literarios (3.1), elementos filosóficos y sabiduría bíblico-teológica (3.2) relativos a la antropología (3.2.1) y a la política (3.2.2), provenientes de los Padres de la Iglesia, en vista de promover la renovación religiosoespiritual y cultural de clérigos, religiosos y laicos. Para ello, emplearemos una metodología cualitativa sincrónica que aplique Análisis Literario Moderno con el fin de ofrecer una exposición descriptivocomparativa de los textos dantescos y de las posiciones de algunos estudios contemporáneos.

Palabras clave: Dante, Padres de la Iglesia, literatura, filosofía, teología, exegesis, Biblia, ser humano, política.

\section{Dante and the Fathers of the Church. General and Particular}

Abstract: In his works, Dante shows an intellectual formation which important presence and influence of history and cultural production of the Late Antique Christianity. This was acquired by

* Giancarlo Bellina Shols es patrólogo, profesor investigador de la UCSS, editor de la Revista de Teología Pastoral Pastores del Nuevo Milenio del ISET Juan XXIII, y profesor de Educación de la Fe y Teoría del Conocimiento (Programa Bachillerato Internacional) en el Colegio Sagrados Corazones Recoleta. Ha estudiado en el Augustinianum de Roma (Teología y Ciencias Patrísticas), en la Xaveriana de Bogotá (Investigación Teológica) y, actualmente, en la PUCP de Lima (Filosofía). Sus intereses giran en torno a la antropología patrística, la evangelización de la cultura y la educación en la antigüedad tardía.

** El autor agradece la corrección de estilo del Abstract a Mercerdes Olinda Sangio Alonso. 
studying both works of his contemporaries as the same patristic texts. In these pages I explain some general (2) and particular (3) aspects of his formation and production in order to show how the Father of the Italian language estimates and uses the literary models (3.1), the philosophical elements and the biblical-theological wisdom (3.2), concerning to antropology (3.2.1) and politics (3.2.2) coming from the Father of the Church, to promote the religious-spiritual and cultural renewal of clergy, religious and laity. To do this, I use a synchronous qualitative methodology applying modern literary analysis to offer a comparative-descriptive exposition of the Dante texts and the positions of some contemporary studies.

Keywords: Dante Alighieri, Father of the Church, literature, philosophy, theology, exegesis, Bible, human, politics.

\section{Introducción}

gradezco a la Universidad Católica Sedes Sapientiae la oportunidad de compartir con
ustedes, en el contexto de la conmemoración dantesca, algunos aspectos que pueden iluminar la relación que el Padre de la lengua italiana supo mantener con los Padres de la Iglesia. Claro está, nuestra circunstancia solo nos permitirá abordar pocos aspectos con algo más de sutileza. Tomo como modelo de esta labor al desaparecido humanista Julio Picasso, amigo y maestro, quien, con sus publicaciones, ha cultivado y nos ha hecho gustar de algunos frutos de ambas tradiciones literarias, la tardo-antigua y la medieval.

Y desde ya, deseo presentar mi intención. Pretendo, al señalar ciertos detalles de la vida y de las obras de Dante en relación con personajes e ideas provenientes del cristianismo antiguo, llamar la atención acerca de la influencia dominante de estos en la vida intelectual y espiritual de la Europa medieval. Más que pretender reconstruir con exactitud una supuesta "Biblioteca Patrística” de Dante, deseo considerar aspectos de la vida y de las obras del poeta, para construir relaciones y explorar reminiscencias de textos patrísticos.

Aquí en Perú es común soslayar este aspecto cuando se estudia el Medioevo: a lo más se lo menciona, pero no se profundiza en ello. Y no me refiero tanto al gran trabajo científico de verificar los detalles de tal influencia, sino, en general, al vacío que en la práctica se expresa cuando la época tardo-antigua —en efecto, la época de los Padres de la Iglesiaes casi pasada por alto en los cursos historiográficos referentes a tales épocas. Por ejemplo, en clases de filosofía, se suele pasar a san Anselmo o santo Tomás casi solo profundizando en un autor tardo-antiguo, san Agustín, y sin contextualizar con suficiencia. En este caso también podríamos decir que el desinterés es solo ignorancia. 
Sin negar el puesto dominante que este último autor tiene, lo cierto es que la influencia patrística en el Medioevo es variada, tanto en la temática como en los autores, no solo latinos (como san Ambrosio, Boecio, san Gregorio Magno) sino también griegos traducidos al latín (de entre los cuales descuellan el Pseudo-Dionisio; los padres capadocios, Gregorio de Nacianzo, Gregorio de Nisa, Basilio Magno; y más adelante Juan Damasceno). Es decir, el hombre medieval vivía al interior de una tendencia común de apertura hacia la tradición patrística. Pasar por alto este aspecto o — dado el caso— renunciar ideológicamente a afrontar la cuestión de la influencia patrística en los medievales, a causa de otros intereses, significa renunciar a una comprensión profunda de los autores medievales (Crouse, 2008).

Para este trabajo, citamos las obras revisadas de Dante usando las siguientes abreviaturas: If (Inferno), Pg (Purgatorio), Pr (Paradiso), Cv (Convivio), VE (De vulgari eloquentia), Ep (Epistula), Mn (Monarchia). Para las obras de otros autores antiguos, tardoantiguos y medievales, mantenemos los títulos completos. Hemos traducido al español y revisado cada texto de Dante siguiendo las ediciones críticas de Barbieri, Cecchin, Jacomuzzi \& Stassi, 1983; Chiappelli \& Fenzi, 1986; Chimenz, 2003; Gaia, 1986; Jacomuzzi, 1986.

\section{Formación y Estima}

omencemos entonces recordando la formación intelectual del Sumo Poeta. La vida
y producción de Dante, hacia finales del siglo XIII y primeras décadas del siglo XIV, tiene como marco una vida intelectual enriquecida por muchas obras antes desconocidas. Me refiero a textos aristotélicos, platónicos y, claro está, patrísticos.

A la par con otros autores a él contemporáneos, Dante buscó obtener una síntesis coherente lograda a partir de estas tradiciones culturales y de los clásicos. Así, llegó a conseguir un saber enciclopédico inmenso y un pensamiento ecléctico, que le hizo capaz de reutilizar con naturalidad, en sus obras, lo clásico en contexto medieval y lo originalmente pagano en vista de la intelección de la fe cristiana. Por ello, haríamos mal en ser exclusivos en este caso y pretender entender a Dante solamente desde sus conocimientos patrísticos. En efecto, también se reconoce al poeta como un óptimo interlocutor de sus contemporáneos.

Recordemos que su derrotero formativo juvenil lo llevó, desde el interés por la poesía (estudiando en la escuela a los poetas latinos) hasta el estudio de la filosofía y de las ciencias, estimulado por Brunetto Latini y Guido Cavalcanti, grandes impulsores culturales florentinos. Con ellos aprendió a cantar el amor espiritual, en un dolce stil nuovo, atento 
al crecimiento intelectual y virtuoso, sumando por su cuenta un particular contenido teológico-religioso. Su formación continuó en el periodo 1287-1288 en el Studio delle Arti di Bologna (pues Florencia no contaba con un studium urbis), bajo la influencia de Guido Guinizzelli, entre otros.

Pero parece que sus intereses filosóficos experimentaron un impulso decisivo, según él mismo expone en el libro II del Cv, aunque sin ofrecer muchas noticias sobre "autores" y "libros", cuando, en busca de consuelo por la muerte de su amada Beatriz (mediados del 1290), leyó la Consolatio philosophiae (Pérez, 1997) de Boecio junto con el De amicitia de Cicerón (Micunco, 2007) (Cv II, 12, 1-7; II, 15, 1). Desde aquel momento, Dante consideró a la filosofía como una "somma cosa", representándola bajo la figura boeciana de la "donna gentile" y "misericordiosa" (Vasoli, 2006).

En ese mismo apartado del Cv, Dante nos informa que, en el periodo 1290-1295, yendo en busca de "filosofía veraz", asistió a las "scuole de li religiosi" y a las "disputazioni de li filosofanti” en Florencia. Podría también estar refiriéndose a escuelas de Boloña, pues recordemos que Boccaccio nos informa que Dante volvió a Boloña entre los años 1292 y 1294 (Trattatello in laude di Dante III, edición Sasso, 1995). Ahora bien, según los estudiosos, con tales expresiones seguramente hace referencia a tres escuelas "religiosas" —es decir, pertenecientes a órdenes mendicantes - florentinas de nivel universitario.

Estas escuelas son las siguientes. Tenemos el Estudio Dominicano de Santa Maria Novella, donde habría profundizado en las obras de Alberto Magno y Tomás de Aquino; entre ambos, según estudios recientes, Alberto fue quien por momentos influyó más en su formación filosófica y científica (Vasoli, 2006; Franke, 2010a; Botterill, 2010). Luego, el Estudio Franciscano de la Santa Croce, cuya línea de pensamiento era más bien influenciada por las doctrinas de Agustín, de Buenaventura y de los místicos de aquella orden (Vasoli, 2006; Chiappelli \& Fenzi, 1986). La última corresponde al Estudio Agustiniano de Santo Spirito (Davis, 1986), donde se profundizaba el pensamiento del Obispo de Hipona junto con las obras de Egidio Romano, declarado doctor oficial de la Orden Agustina en el Capítulo General de Florencia de 1287 (Punta, Donati \& Luna, 1993). Al interior de estos ambientes conventuales, Dante acudió, no a las clases, sino a los debates de carácter filosófico con evidente tendencia teológica (Chimenz, 1960; Mazzotta, 2010; Davis, 1988; Bertelloni, 2008).

Se han dado muchas propuestas al respecto, a través de reconstrucciones sea de carácter histórico sea de la biblioteca de Dante, con el fin de poder dar con las quaestiones 
y las auctoritates involucradas en estas "disputazioni de li filosofanti” que el poeta frecuentó. Queda mucho por dilucidar acerca de las tendencias filosóficas y de las Bibliotecas de aquellos lugares en aquella época (Bertin, 2014; Davis, 1986; Brunetti \& Gentili, 2000). Nada es seguro acerca de los maestros que tuvo en estas escuelas, aunque podrían inferirse los nombres del dominico Remigio dei Girolami y de los franciscanos Pietro di Giovanni Olivi y Ubertino da Casale (Ghisalberti, 1996).

Con todo, lo que no puede negarse es que en estas décadas de formación, en la que su poesía y su prosa fueron enriquecidas por la filosofía y la teología, Dante visitó, tanto en Florencia como en Bolońa, diversas bibliotecas de corte, de universidades, conventuales y privadas, con el fin de contar no solo con florilegios o enciclopedias sino también, y sobre todo, con obras completas, textos filosóficos y teológicos de su interés (Bertin, 2014). Tampoco puede descartarse que, entre las lecturas realizadas por el Sumo Poeta en este periodo, hubo obras patrísticas y contemporáneas a él consagradas como altos modelos de una cultura cristiana enriquecida por y transmisora de elementos filosóficos. En efecto, el florentino demuestra en sus obras no solo admiración por los filósofos y sus textos, sino también por los doctores eclesiásticos, también antiguos.

El bagaje dantesco acerca de la historia del cristianismo antiguo se constata fácilmente. Por ejemplo, se verifica tomando en cuenta a los personajes propios de esta época presentes en su Commedia:

- Los papas Anastasio II (If XI, 1-12), Lino (Pr XXVII, 41), Anacleto (Pr XXVII, 41), Sixto (Pr XXVII, 44), Pío (Pr XXVII, 44), Calixto (Pr XXVII, 44), Urbano (Pr XXVII, 44), Agapito (Pr VI, 16) y Silvestre (Pr XX, 57);

- los emperadores Justiniano (Pr V, 115; VI, 1-142; VII, 5-7), Trajano (Pg X, 7381; Pr XX, 43-48 y 106-107) y Constantino (Pr VI, 1; XX, 55.57);

- los escritores Pseudo-Dionisio (Pr X, 115-117; XXVIII, 130); Boecio (Pr X, 124129); Paolo Orosio (Pr X, 119); Isidoro de Sevilla (Pr X, 131); Beda el Venerable (Pr X, 131); Benito de Nursia (Pr XXII, 19-69 y XXXII, 35); Agustín de Hipona (Pr X, 120 y XXXII, 35); Juan Crisóstomo (Pr XII, 136-137); Gregorio Magno (Pr XXVIII, 133); Jerónimo (Pr XXIX, 37);

- los griegos Macario Abad (Pr XXII, 49), Nicolás de Mira o de Bari (Pg XX, 32);

- los herejes Arrio y Sabelio (Pr XIII, 127). 
En la misma Commedia encontramos de alguna manera una representación de las preferencias del poeta entre los escritores cristianos tardo-antiguos. Dante es cuidadoso al escoger, bajo los criterios eclesiales de la ortodoxia y de la santidad de vida, a quién mencionar. Así, es significativa la gradatio que nos transmite en el $\operatorname{Pr}$ (Ghisalberti, 1996):

- Entre los que forman parte de las dos grandes coronas de doce espíritus sabios cada una en el IV Cielo (Pr X, 94-148 y XII, 127-145), que testimonian en el cielo la continuidad de la Iglesia en la tierra, se encuentran siete autores de época patrística cuyos textos estaban muy presentes en las universidades medievales: Pseudo-Dionisio, Paolo Orosio (o Lactancio, o sino Ambrosio; o mejor, Mario Victorino), Boecio, Isidoro de Sevilla, Beda el Venerable, Juan Crisóstomo y el gramático Elio Donato;

- sobre ellos, en el Empireo, entre las almas contemplativas del VII Cielo, aparece el abad Benito de Nursia (Pr XXII, 19ss);

- finalmente, entre los beatos distribuidos en la Candida Rosa, al X Cielo, Dante coloca a Benito de Nursia y Agustín de Hipona (Pr XXXII, 35).

Además, contamos con dos textos en los que Dante expresa, con su estilo, esta admiración, junto con la urgencia de leerlos. En efecto, cabe mencionar que la conexión con los Padres de la Iglesia tiene en Dante un aspecto práctico, urgente y religioso: traer de ellos motivos para promover la renovación eclesial. El primer texto es el siguiente:

En cambio, [entre las escrituras] contemporáneas a la Iglesia se encuentran aquellos concilios principales que deben ser venerados, en los que estuvo presente Cristo, cosa que ningún creyente duda (...). También [entre estas escrituras contemporáneas] se encuentra los escritos de los doctores, Agustín y otros, quienes escribieron ayudados por el Espíritu Santo, y quien dude [de esto], o nunca ha visto sus frutos, o, si los ha visto, nunca los ha gustado.

Cum Ecclesia vero sunt veneranda illa concilia principalia quibus Cristum interfuisse nemo fidelis dubitat [...] Sunt etiam Scripture doctorum, Augustini et aliorum, quos a Spiritu Sancto adiutos qui dibuat, fructus eorum vel omnino non vidit vel, si vidit, minime degustavit. (Mn III, 3, 13-14, edición Gaia, 1986, pp. 700-701) 
Este texto aquí transcrito y traducido forma parte de la presentación de la conocida teoría dantesca de las tres escrituras, con la cual, sin negar veneración a alguna, se propone una gradatio entre ellas: "Una [escritura] anterior a la Iglesia, otra contemporánea, y una tercera posterior a la Iglesia” (Mn III, 3, 11). Los escritos patrísticos están colocados, junto con los concilios principales antiguos en los que estos Padres participaron, al interior de la "Scriptura cum Ecclesiam", después del Antiguo y Nuevo Testamento que conforman la "Scriptura ante Ecclesiam", pero antes de la "tradición de los decretales" que Dante coloca en la "Scripura post Ecclesiam", pues "la tradición debe ir después".

Siguiendo a Gaia (1986) podemos decir que, para Dante, los escritos de los Padres forman parte de los fundamentos de la fe. La razón es que estos conservan y explican lo constituido previamente en el Antiguo y en el Nuevo Testamento, al interior de la Iglesia. La presentación de esta relación resulta más estrecha y hasta natural por medio de la mención del Espíritu Santo que ha inspirado tanto a los Padres como a los hagiógrafos, lo que a Lubac (1972) parece exageración.

Se trata, pues, de escrituras emparentadas a través de un mismo origen divino —al igual que los concilios en los que estuvo presente Cristo-, aunque una siempre preceda a la otra. A fin de cuentas, todo ello explica la posibilidad del "senso mistico". En efecto, en Mn (III, 4, 6-11), Dante cita el De civitate Dei (XVI, 2, edición Morán, 1958) y el De doctrina christiana (I, 36, edición Martín, 1957a) de san Agustín para señalar dos errores que pueden cometerse al aplicar el "senso mistico" — lo revisaremos más adelante—. Solo la ignorancia (no conocer sus frutos o no haberlos gustado) explica, para Dante, el desinterés respecto a estos escritos.

Todo ello forma parte de la argumentación dantesca anti-decretalista y anticanonista de quienes, por motivos mundanos, siguen la bula Unam Sancta del Papa Bonifacio VIII y sostienen que la autoridad imperial desciende de la Iglesia y del pontífice romano. Tal idea es contraria al Nuevo Testamento. También es contraria a los cánones de los concilios antiguos y al consensus patrum (Vasoli, 2006).

$\mathrm{Al}$ respecto, encontramos otro texto ejemplar en la Ep XI (año 1314), una de las llamadas "cartas políticas" dirigida a los Cardenales italianos en cónclave. Este texto presenta el tema de la purificación interior de la Iglesia, en concreto se critica la riqueza de Florencia y la avidez de los eclesiásticos y curiales. Para ello, Dante se adhiere a la tradición cristiana, que considera rica y consolidada, con el fin de extraer normas y modelos. 
Dicho de otra manera, para el florentino, la vida y la sabiduría bíblica y teológica de los Padres son exempla para su argumentatio. En efecto, en su polémica anti-curial, cobra vigencia el modelo eclesial bíblico y patrístico de la Esposa — pobre- de Cristo pobre, modelo contrario a la avaricia. Al respecto, en la Commedia, señala que en su tiempo la tradición jurídica resultaba tan importante que llevaba al olvido a "l'Evangelio e $i$ dottor magni" (Pr IX, 133-135; al respecto también Mn III, 3), es decir, a la Palabra de Dios y a su correlato, los Padres de la Iglesia (Jacomuzzi, 1986; Havely, 2010), tal como lo acabamos de presentar. Como expresión y refuerzo de estas ideas tenemos el texto de la Ep en cuestión:

¿Acaso no es así? Cada uno — y también ustedes — ha tomado por esposa a la codicia, la cual nunca es, como la caridad, madre de la piedad y de la equidad, sino que siempre lo es de la impiedad y de la iniquidad. Oh madre piísima, esposa de Cristo, que generas a tus hijos en agua y espíritu para tu vergüenza. No la caridad, no Astrea, sino las hijas de la Sanguijuela [Pr 30,15] se te han convertido en nueras, y qué tipo de hijos te nacen lo demuestran, a excepción del obispo de Luni, todos los demás. Yace tu Gregorio entre las telarañas; yace Ambrosio en los armarios abandonados de los clérigos; yacen descuidados Agustín, Dionisio, Damasceno y Beda; e Inocencio y el Ostiense aclaman no sé qué tipo de Espejo. ¿No es así? Aquellos buscaban a Dios como fin y sumo bien; estos consiguen prebendas y beneficios.

Quidni? Cupiditatem unusquisque sibi duxit in uxorem, quemadmodum et vos, que nunquam pietatis et equitatis, ut caritas, sed semper impietatis et iniquitatis est genetrix. A, mater piisima, sponsa Christi, que in aqua et Spiritu generas tibi filios ad ruborem! Non caritas, non Astrea, sed filie sanguisuge facte sunt tibi nurus; que quales pariant tibi fetus, preter Lunensem pontificem omnes alii contestantur. Iacet Gregorius tuus in telis aranearum; iacet Amborsius in neglectis clericorum latibulis; iacet Augustinus abiectus, Dionysius, Damascenus et Beda; et nescio quod 'Speculum', Innocentium, et Ostiensem declamant. Cur non? Illi Deum querebant, ut finem et optimum; isti census et beneficia consecuntur. (Ep XI, 7, edición Jacomuzzi, 1986, pp. 426-427)

Tocando solo lo que nos interesa, en este párrafo Dante se lamenta de que los obispos y cardenales de su tiempo se dediquen casi exclusivamente a codiciar bienes 
terrenos, y abandonen y olviden las enseñanzas de los Padres latinos y griegos, sobre todo los mencionados. Y en esto Dante es cuidadoso al provocar el contraste, mencionando Padres que fueron ejemplares tanto en su vida como en promover la re-organización y renovación espiritual de sus propias iglesias. En efecto, se trata, en su mayoría, de obispos que tienen obras importantes relativas a la formación del clero — con fuerte acento místico- y a su función pastoral.

Este abandono y olvido, es decir, el hecho de no leerlos, ha desorientado a los clérigos de su tiempo, quienes se han vuelto exclusivamente a los "estudiosos de los decretos", quienes son representados por el canonista Papa Inocencio IV y el maestro de derecho canónico Enrique de Susa obispo de Ostia. La consecuencia de ello es una Iglesia que solo vela por lo material y temporal. Asimismo, se trata de una Iglesia que olvida el camino de la pastoral y de la oración contemplativa (Jacomuzzi, 1986; Crouse, 2008).

\section{Aspectos Particulares}

Continuemos presentando la admiración e interés dantescos por los Padres desde un desarrollo que siga la triple vertiente de su formación, es decir, literaria, filosófica y teológica. Y esto es posible porque esta admiración y este interés eran completos: para Dante, las obras de los Padres valían como modelos literarios, fuentes de conocimientos filosóficos válidos y transmisores de una teología irreprochable.

\subsection{Literatura}

Respecto a lo literario, Dante extrae de la tradición literaria cristiana antigua tanto normas como modelos estilísticos, habiéndose formado retóricamente a partir de los ejemplos y usos de los Padres de la Iglesia, junto con los textos con los que los Padres estudiaron la retórica, como las obras de Cicerón. Así, señala la prosa de Paulo Orosio como exemplum (VE II, 6, 7) y, en cuanto a la métrica y uso de metáforas en poesía filosófica, Dante, en su Commedia, sigue de cerca la Consolatio boeciana (Lobardo, 2008; Tateo, 1970; Pérez, 1997). Otros exempla son Boecio y Agustín de Hipona, acerca de por qué y para qué hablar de sí mismo: 
Los rétores a nadie conceden hablar de sí mismo, salvo por necesidad, y así todo hombre es alejado de esto, pues no se puede hablar de alguien sin alabarlo o culpabilizarlo [por algo] (...). Y entre las razones necesarias hay dos especialmente llamativas. Una, cuando, sin poder evitarlo, se habla de sí mismo sin gran desgracia o peligro; (...). Y esta necesidad tuvo Boecio al hablar de sí mismo [en su Consolatio philosophiae] para que, con el pretexto de encontrar consuelo, podría paliar la desgraciada duración de su exilio, demostrando que esto era injusto (...). Otra necesidad surge al tener que hablar sobre uno mismo para gran ventaja de los demás; esta fue la razón que hizo que Agustín hablara de sí mismo en sus Confessiones [Confessiones X, 3, 4, edición Vega, 1979], para que, a través del progreso de su vida (...) nos sea dado ejemplo y enseñanza.

Non si concede per li rettorici alcuno di sé medesimo sanza necessaria cagione parlare, e da ciò è l'uomo rimosso, perché parlare d'alcuno non si può che il parladore non lodi o non biasimi quelli di cui elli parla (...) e intra l'altre necessarie cagioni due sono più manifeste. L’una è quando sanza ragionare di sé grande infamia o pericolo non si può cessare; (...). E questa necessitate mosse Boezio di sé medesimo a parlare, acciò che sotto pretesto di consolazione escusasse la perpetuale infamia del suo essilio, mostrando quello essere ingiusto (...). L'altra è quando, per ragionare di sé, grandissima utilitade ne segue altrui per via di dottrina; e questa ragione mosse Agustino ne le sue Confessioni a parlare di sé, ché per lo processo de la sua vita (...) ne diede essemplo e dottrina. (Cv I, 2, 3-4.12-14, edición Chiappelli \& Fenzi, 1986, pp. 69-71)

Desarrollemos ahora otro aspecto, ya señalado en la sección anterior, a saber, la fuente del "senso mistico" en la común inspiración divina de los Testamentos y de los escritos de los Doctores, Agustín y otros. Aunque originalmente bíblico-teológico, este aspecto en Dante presenta una finalidad literaria, relativa a la interpretación de los cantos en el Cv y a la característica "polisemos - plurium sensuum" de la Commedia (Lubac,1972, pp. 1535-1540; Ghisalberti, 1996, pp. 303-306), considerada un poema teológico. En efecto, en Cv II, 1, 2-15 y Ep XIII, 7, el Sumo Poeta expone, con tono algo religioso (Lubac, 1972) y filosófico, los quattro sensi posibles de explicación de una escritura, a saber, literal o histórico, místico o alegórico, y como división de este, alegórico en cuanto tipológico, moral y anagógico.

Ambas exposiciones señalan y repiten que el orden de las cosas exige tanto una racionalidad según la cual el sentido literal sea la base y preceda a los demás sentidos, como 
el contenido crístico y la finalidad espiritual de los sentidos místicos o alegóricos. Al respecto, los estudios señalan como fuente a Tomás de Aquino con los textos Quolibet VII, q. 6, art. 15 (Gauthier, 1996); Super Epistolam Pauli Ad Galatas Lectura c. V, lect. 7 (Abascal, 1982); y Summa Theologiae I ${ }^{a}$, q. 1, art. 10 (Suárez, R. \& Muñiz, 1947). En Tomás se trata de un sentido literal o histórico y otro espiritual o místico que se divide en tres, a saber, moral o tropológico, alegórico o tipológico, y anagógico. Con todo, podríamos decir que son los Padres por medio de Tomás que influenciaron en Dante, pues Tomás, para esta presentación, sigue la doctrina de los Padres acerca de estos cuatro sentidos, por ejemplo, el De utilitate credendi 3, 5-9 de Agustín de Hipona (Lubac, 1972; Agustino, 1956).

Al respecto, tampoco podemos descartar la lectura directa de autores patrísticos como base de estas presentaciones. Por ejemplo, uno de ellos podría ser Gregorio Magno, quien, en su Carta Dedicatoria al obispo Leandro de Sevilla con motivo de sus Moralia in Iob (Moralia, Carta dedicatoria 3, edición Gillet \& Gaudemaris, 1950), expone estos sentidos de interpretación. De este mismo Padre y Doctor de la Iglesia, parece que Dante tomó la intelección del uso de la alegoría como el recurso a una "machinam" (Super Canticum Canticorum, proemium 2, edición DelCogliano, 2012) que eleva el alma a Dios y la transporta, desde su miseria hasta la felicidad plena (Martínez, 2010). Veremos este último aspecto en el siguiente apartado.

Se suele señalar también a Tomás (Quolibet VII, q. 6; Gauthier, 1996) como fuente de la distinción que Dante hace entre la alegoría de los poetas y la alegoría de los teólogos, al afirmar que

i teologi questo senso [aquí senso hace referencia a la metáfora poética al interior del intencional sentido literal, que solo puede ser vertical y verdadero en el otro nivel] prendono altrimenti che li poeti [pues para el teólogo uno es el sentido literal y otro el alegórico, este último como metáfora continuada a otro nivel que el de la letra y que no solo es vertical sino también horizontal, tipológico, y que puede ser verdadero a todo nivel]. (Cv II, 1, 4, edición Chiappelli, \& Fenzi, 1986, p. 104)

Con todo, una vez más, la fuente parece ser Agustín de Hipona detrás de Tomás, con su distinción entre la "allegoria in verbis" — de la literatura pagana — y la "allegoria in facto" de la literatura sagrada (Ga 4, 21-31)—(De Trinitate XV, 9, 15, edición Arias, 1956; Teuber, 
2009). Permanece en ello la idea de que el poeta pagano no utiliza la alegoría teológica, y que el teólogo no utiliza la alegoría poética, pues no conviene a sus intenciones, sin negar que son usos válidos y consagrados al interior de cada tradición literaria. Ante esta situación, el genio de Dante, diferenciando correctamente, integra ambas alegorías en su producción, también en su Commedia, enriqueciéndola con niveles de lectura a modo de un poema doblemente alegórico (Ep XIII, 11, edición Teuber, 2009).

Por lo demás, Dante expresa la autoridad que otorga a los Padres, en concreto a Agustín, sobre el "senso mistico" cuando, en el libro III de Mn lo cita para señalar, como dijimos anteriormente, dos errores que pueden cometerse. El motivo, esta vez, es confutar el argumento que, basado en una interpretación alegórica de Gn 1, 16, sostenía que, por disposición divina, el poder temporal del imperio depende del poder espiritual de la Iglesia así como la luna depende del sol para ser iluminada e iluminar:

(...) al interpretar según el sentido místico, uno puede equivocarse de dos maneras: sea cuando lo buscamos donde no lo hay, sea cuando lo entendemos diversamente de como debería ser entendido. En cuanto al primer [modo de equivocación], Agustín dice en La Ciudad de Dios: "No debe creerse que todos los hechos narrados tengan otro significado (...) [De civitate Dei XVI, 2, edición Morán, 1958]”. Sobre el segundo [modo de equivocación], el mismo autor, en la Doctrina Cristiana, hablando de quien da a las Escrituras un sentido diverso a aquel entendido por quien lo escribió, afirma que este "comete el mismo error de quien, abandonando el justo camino, quisiera sin embargo, yendo de un lado a otro, llegar donde aquel camino conduce (...)" [De doctrina christiana I, 36, edición Martín, 1957a]. Más adelante [Agustín] indica el motivo por el cual es necesario cuidarse de estos errores al interpretar las Escrituras, diciendo: "Si vacila la autoridad de las Sagradas Escrituras, la fe titubeará" [De doctrina christiana I, 37, edición Martín, 1957a]

(...) quod circa sensum misticum dupliciter errare contingit: aut querendo ipsum ubi non est, aut accipiendo aliter quam accipi debeat. Propter primum dicit Augustinus in Civitate Dei: "Non omnia que gesta narratur etiam significare aliquid putanda sunt (...)". Propter secundum idem ait in Doctrina Cristiana, loquens de illo aliud in Scripturis sentire quam ille qui scripsit eas dicit, quod "ita fallitur ac si quisquam deserens viam eo tamen per pergeret quo via illa perducit 
(...)". Deinde innuit causam quare cavendum sit hoc in Scripturis, dicens: "Titubabit fides, si Divinarum Scripturarum vacillat autoritas. (Mn III, 4, 6-10, edición Gaia, 1986, pp. 706-709)

\subsection{Filosofía y teología}

Pasemos a considerar algunos aspectos filosófico-teológicos. En cuanto a la filosofía, recordemos que el poeta en su $\mathrm{Cv}$, de muchas maneras, señala que una de sus intenciones es volgarizzare la filosofía. Esto quiere decir que esta, entendida como la sabiduría que el hombre ama y que perfecciona su alma y la hace alcanzar la felicidad verdadera y especulativa en la unión con Dios (Cv I, 1, 1-15; III, 1ss; Bertelloni, 2008; Vasoli, 2006), llegue a quienes no hablan latín (Pérez, 2012).

Esta filosofía es descubierta en y procede de autores cristianos y paganos. En efecto, ambas tradiciones están representadas por la Consolatio de Boecio (Pérez, 1997) y por el De amicitia de Cicerón (Micunco, 2007) en Cv II, 12, 2-3, texto visto al comienzo. Sin ser ni considerarse filósofo de profesión (Cv I, 1, 7-10), Dante recurre no solo directamente a textos filosóficos, sino también a textos patrísticos de uso universitario y a autores escolásticos, con el fin de extraer principios filosóficos y divulgarlos, en una especie de "democratización del saber", pues la filosofía prepara la inteligencia para la fe (Pr IV, 118-132; XIX, 13-45). Entre todos los autores y escuelas (estoicos, epicúreos, académicos), la predilección dantesca recae sobre Aristóteles y los Peripatéticos (Cv IV, 6, 6-16).

Respecto a la teología, Dante expone, en Cv II, 14, que es la "divina scienza", es decir, la ciencia de Dios que Cristo transmitió a sus apóstoles y que solo es cognoscible gracias a la fe. Otro aspecto interesante es la tendencia espiritual y mística de su pensamiento. Así, en la Ep XIII, 20-22; 53-54; 67-68 encontramos una exposición de los cuatro sentidos bíblicos que dan a la Commedia un contenido teológico de ascensión hacia Dios, es decir, de grados consecutivos hasta llegar a la contemplación, la cual se logra no sin recurso a la "ratio philosophica" (Cv III, 7, 17; Ghisalberti, 1996).

Se aprecia así, en Dante, la estrecha relación y convivencia entre ambas ramas del conocimiento, la asimilación del trabajo de la fe que busca el entendimiento, basado en que fe y razón son modos de ver distintos ( $\mathrm{Cv}$ II, 7, 15; Mn II, 7, 4; siendo superior la fe: $\mathrm{Cv}$ III, 3, 15) que provienen de la misma luz divina (Pr XIX, 64-66) y que se complementan. En síntesis, para Dante se trata de la comprensión de la Biblia y de la Tradición Cristiana, 
de lograr establecer, entre la fe (creer, es decir, la fe católica: Pr XXIV, 52-147) y la razón (entender, es decir, especulación filosófica) una relación de mutuo esclarecimiento: la fe — virtud teologal católica — muestra con claridad a la razón lo que la razón solo puede adivinar (Cv III, 15, 6); por su parte, la razón — en su versión filosófica - muestra la racionalidad propia de la fe que se remite a un "intelecto superior" para esclarecer aspectos de la realidad (Cv III, 7; 14, 14; Landoni, 2014, p. 205).

Por momentos Dante parece distanciarlas con fuerza. Por ejemplo, en la Commedia, diferenciando a Virgilio de Beatriz: el primero afirma que enseña a Dante todo lo que la razón humana puede saber, mientras que la segunda es portadora de la fe y así le indica lo que está más allá de la razón (Pg XVIII, 48). También al diferenciar, en Mn III, 16, 8, que es posible alcanzar la felicidad terrena por medio de los "phylosophica documenta", mientras que la felicidad de la vida eterna se alcanza por medio de los "documenta spiritualia quae humanam rationem transcendunt".

Con todo, lo cierto es que la argumentatio dantesca supone un "círculo hermenéutico" entre ellas. Es decir, se trata de un esquema cognoscitivo de correspondencia biunívoca entre fe y razón (Truijen, 1970). Y este esquema históricamente se remonta a Filón de Alejandría, quien lo aplicó para interpretar los contenidos de su fides iudaica a través de una interpretación de los textos sagrados (Antiguo Testamento) con recurso a la ratio philosophica griega, esquema que los Padres de la Iglesia cristianizaron, abriéndose al mundo cultural de su época para acoger herramientas de explicación y de exposición de muchos puntos del misterio cristiano.

El adagio agustino "intellege ut credas, crede ut intelligas" (Sermo 43, 9) sirva como síntesis de esta descomunal labor. Dante, leyendo autores cristianos antiguos, pudo profundizar y conocer ejemplos del modo de proceder al interior de este esquema ya cristianizado y ampliamente conocido en su época. Podemos señalar primero aspectos de su antropología para luego pasar a su expresión política.

\subsubsection{Antropología}

Comencemos considerando un texto emblemático:

Para entender esto, debemos observar que solo el hombre ocupa un lugar intermedio entre los seres corruptibles y los incorruptibles, por lo que justamente es comparado por los filósofos con el horizonte que se encuentra 
en medio de los dos hemisferios. En efecto, el hombre es corruptible si es considerado según sus dos partes esenciales, a saber, alma y cuerpo; [en cambio,] es incorruptible si es considerado según una [de sus partes], a saber, el alma. Por esto, el Filósofo dice rectamente, en el libro II del De anima, respecto a esta parte incorruptible, que "en cuanto inmortal, solo esta parte puede separarse de la parte corruptible" [De anima II, 2, 413b 26]. Por tanto, si el hombre es [un ser] intermedio entre los que son corruptibles y los que son incorruptibles, y dado que todo ser intermedio conoce la naturaleza de los extremos, es necesario que el hombre conozca ambas naturalezas. Y dado que cada naturaleza está ordenada hacia su último fin, se concluye que en el hombre existe un doble fin, de tal manera que él es el único entre todos los seres que participa de la incorruptibilidad y la corruptibilidad, y así, es el único entre todos los seres que está ordenado con relación a dos fines últimos, a saber, con relación a un fin en cuanto es corruptible, y con relación a otro [fin] en cuanto es incorruptible.

Por tanto, aquella indescriptible providencia ha preestablecido para el hombre dos fines a los que tender: la felicidad de esta vida, simbolizada por medio del paraíso terrestre, que consiste propiamente en practicar [vivir según] la virtud; y la felicidad de la vida eterna, entendida como el paraíso celestial, que consiste en el disfrute de la visión de Dios, a lo que no se puede elevar la virtud propia [del hombre], sino con la ayuda de la luz divina.

Ad huius autem intelligentiam sciendum quod homo solus in entibus tenet medium corruptibilium et incorruptibilium; propter quod recte a phylosophis assimilatur orizonti, qui est medium duorum emisperiorum. Nam homo, si consideretur secundum utranque partem esentialem, scilicet animam et corpus, corruptibilis est; si consideretur tantum secundum unam, scilicet animam, incorruptibilis est. Propter quod bene Phylosophus inquit de ipsa, prout incorruptibilis est, in secundo De anima cum dixit: "Et solum hoc contigit separari, tanquam perpetuum, a corruptibili". Si ergo homo medium quoddam est corruptibilium et incorruptibilium, cum omne medium sapiat naturam extremorum, necesse est hominem sapere utranque naturam. Et cum omnis natura ad ultimum quendam finem ordinetur, consequitur ut hominis duplex finis existat: ut, sicut inter omnia 
entia solus incorruptibilitatem et corruptibilitatem participat, sic solus inter omnia entia in duo ultima ordinetur, quorum alterum sit finis eius prout corruptibilis est, alterum ver prout incorruptibilis.

Duos igitur fines providentia illa inenarrabilis homini proposuit intendendos: beatitudinem scilicet huius vite, que in operatione proprie virtutis consistit et per terrestrem paradisum figuratur; et beatitudinem vite acterne, que consistit in fruitione divini aspectus ad quam propria virtus ascendere non potest, nisi lumine divino adiuta, que per paradisum celestem intelligi datur. (Mn III, 15, 3-7, edición Gaia, 1986, pp. 770-773; el subrayado es nuestro)

Las secciones subrayadas nos permiten afirmar, sin entrar en detalles por cuestiones de espacio, que el modelo antropológico adoptado por Dante es deudor del esforzado, delicado y continuo trabajo de varias generaciones de autores cristianos antiguos. Este consistió en discernir cuidadosamente los elementos antropológicos y éticos de sus culturas (griega y latina) que, no siendo contrarios a la fe, puedan ser integrados en una presentación racionalmente alturada y coherente con el fin de evangelizar al hombre culto de su tiempo sobre todo en tres aspectos: la naturaleza y fin del ser humano, lo que hace en la tierra y lo que hará en el cielo.

La investigación actual ha logrado superar antiguas etiquetas, ciertamente no gratuitas, que desviaron la comprensión de la antropología patrística, sobre todo con relación a la valoración del cuerpo y de sus bienes (vida, salud, integridad). En particular, hoy se estudian los textos patrísticos a través de la tesis reconfirmada según la cual la influencia de la tradición platónica — en concreto, la identificación del hombre con su alma que, en la versión neoplatónica, supone un fuerte alejamiento del cuerpo y un casi exclusivo interés por el alma en vista de la contemplación - en aquella época fue atenuada. Esto se dio primero por la fe judeo-cristiana, y segundo por el aristotelismo y estoicismo de la época.

Así, los aspectos nucleares de este legado cultural patrístico se encuentran en Dante. El hombre es un ser creado y ordenado naturalmente por Dios hacia los bienes que causan su felicidad por medio de una tendencia natural que también es buena. Es un compuesto de alma y cuerpo, por lo que posee un lugar intermedio en los grados del ser — versión dantesca de la medietas ontológica que, en los Padres, correspondía sobre todo al alma humana-, lo que le permite conocer y gustar tanto de los bienes inmateriales-eternos del cielo como de los bienes materiales-temporales del mundo. 
En este compuesto también se preserva un orden, pues la mejor parte es el alma incorruptible que gobierna al cuerpo corruptible y que, a través del intelecto, puede llegar a bienes más altos que los del cuerpo. De ellos, la contemplación de Dios es el más elevado de todos, solo alcanzable con la ayuda divina. Con todo, los bienes del cuerpo son también bienes del ser humano y deben ser atendidos, pero con moderación y sin olvidar la contemplación. Este último punto fue esencial para superar el encratismo tardo-antiguo, es decir, la vivencia de la ascesis al estilo gnóstico que incluía el odio al cuerpo y a lo material como malo, con la consecuente exclusión del matrimonio.

Dante ha podido tomar estos aspectos antropológicos en clara síntesis platónicoaristotélico-estoica, lo repetimos, a través de la lectura directa de textos patrísticos, como por ejemplo, las obras agustinas. En efecto, en estas se expone una antropología cristiana sin odio al cuerpo ni al sexo, sino con un fino ideal de equilibrio-comunión, orden y deificación, alcanzable en el alma con el cuerpo, en el alma consigo misma, y en el alma con Dios (tal como en Cv III, 2, 14-16), siempre contando con la gracia (Cipriani, 2007).

Para reconfirmar esto, podemos citar Cv IV, 21, 14, donde, después de señalar que Dios da su don al hombre en conformidad con su naturaleza y su fin último, a modo de semilla septiforme (a saber, los siete dones del Espíritu Santo), y que, ante ello, el hombre debe ser tierra preparada y trabajar como cultivador para dar el fruto previsto, Dante menciona a Agustín de Hipona —refiriéndose posiblemente al De ordine II, 8, 25 (Chiappelli \& Fenzi, 1986; Capánaga, 1969) u otras obras como De animae quantitate, Confessiones o De civitate Dei, que Dante muestra conocer - junto con el libro II de la Ética de Aristóteles (Lledó \& Palli 1985) para subrayar la necesaria vida virtuosa y la finalidad del "appetito de l'animo", a saber, la felicidad:

Sin embargo, San Agustín quiere, y también Aristóteles en el segundo [libro] de la Ética, que el hombre se acostumbre a actuar bien y refrenar sus pasiones, acción que se llama brote, el cual se fortalece con la costumbre y se confirma en su rectitud, de tal manera que pueda fructificar, y salir de su fruto la dulzura de la felicidad humana

E però vuole santo Augustino, e ancora Aristotile nel secondo de l'Etica, che l'uomo sausi a ben fare e a rifrenare le sue passioni, acciò che questo tallo, che detto è, per buona consuetudine induri, e rifermisi ne la sua rettitudine, si che possa fruttificare, e del suo frutto uscire la dolcezza de l'umana felicitade. (Cv IV, 21, 14, edición Chiappelli \& Fenzi, 1986, pp. 285-286) 
El contexto teológico-moral del párrafo señala que la fuente de estas ideas es Agustín. Asimismo, indica que Aristóteles la refuerza en cuanto a su racionalidad. En efecto, la mención del don de Dios sobrepasa el horizonte aristotélico de la virtud humana, con la confesión de fe acerca del Dios que acompaña y hace posible, con su ayuda, que el esfuerzo del hombre alcance el crecimiento en la virtud con miras a la felicidad.

Así pues, no solo es posible, sino cierto que Dante leyó obras patrísticas con contenido específicamente antropológico. Ofrecemos otra confirmación. El poeta alude, como auctoritas relativa a la contemplación, el parágrafo 33, 76 del De animae quantitate de Agustín de Hipona (Cuevas, 1963) en su Ep XIII, 28, demostrando conocimiento sobre el contenido de este diálogo filosófico. En verdad bastaría esta obra para descubrir los aspectos más centrales de la antropología agustina. Podemos seleccionar la categoría filosófica ordo al interior de tal construcción cristiana tardo-antigua en busca de comprender la realidad del hombre y su relación con los otros seres (De animae quantitate 15, 25; 34, 78; 35, 79 y 36, 81, edición Cuevas, 1963; el De ordine -II, 5, 17; 8, 25; 18, 47, edición Capánaga, 1969-, otro diálogo filosófico agustino, sería fuente más específica).

En resumen, se trata del siguiente desarrollo: el tema del orden de la creación y la jerarquía de los seres —ordo rerum u ordo naturae — y, en relación con cada grado de esta jerarquía, la correspondencia con grados de conocimiento -ordo eruditionis u ordo disciplinarum, ciencia ordenada o subordinada en vista de alcanzar sapientia - y grados en el orden en el deseo humano —ordo amoris, amor-disfrute (frui) de Dios Belleza y uso (uti) de las cosas creadas bellas en Dios- A fin de cuentas, se trata de un ordo vitae en tensión hacia el ideal del homo ordinatissimus que descubre, desea y dirige su vida siguiendo este orden señalado. De esta manera, ocupándose el alma en cada grado, gobernando el cuerpo y no al revés, puede desarrollarse y alcanzar ordenadamente la felicidad — beatitudo — de la contemplación ya en esta vida, para que no termine siendo un "deseo natural insatisfecho".

Esta actividad contemplativa supone y consiste en lo siguiente: el ser humano descubre una multiplicidad ordenada, a saber, grados de bondad y belleza en lo creado que, a modo de peldaños, sirven para ascender con la inteligencia por los grados del ser participado hasta llegar, con la ayuda imprescindible de la gracia, al acto o quiete de la contemplación. Es decir, alcanza la visión del Ser-Uno sin gradación y fuente del ser de los otros seres, del Sumo Bien y Suma Belleza fuente de la bondad y belleza de los otros seres buenos y bellos. Una vez más, no se intenta negar otras fuentes contemporáneas a Dante; al respecto se suele remitir al Sententia Libri Ethicorum liber I, lectio 1 de Tomás de Aquino 
(Perotto, 1998), citado, por lo demás, en Cv IV, 8, 1. Lo que aquí se pretende es mostrar que lo que Dante leía en sus contemporáneos podría haberlo confrontado e iluminado con textos patrísticos.

Es cierto que en el texto de la Mn antes trascrito la mencionada graduación de los seres está implícita. Se la puede notar mejor en el uso de la categoría ordo presente en la Commedia y en el Cv (Durling 2010; Stephany, 2010; Gardner, 1968). En Dante encontramos desarrollos relativos al ordo mundi, es decir, aquella disposición ordenada de cada ser que compone el cosmos, establecida por la sabiduría y providencia de Dios $(\mathrm{Cv}$ I, 4, 3 y 5, 4.11-12; II, 4, 13 y 14, 15-16; III, 3, 3 y 5, 21-22; Pr I, 103-104; IX, 105; X, 1-21; Ep V, 29), que el hombre encuentra — ya establecido- en sus aspectos lógicos, físicos y metafísicos (Cv IV, 9, 6).

Respecto al ser humano, Dante afirma que Dios ha preestablecido los medios de su perfección en el amor ordenado de la verdad y de la virtud, y el gobierno que ejerce sobre los seres que le son inferiores (Cv III, 3, 2-6), ideas inspiradas sin duda en las Confessiones (XIII, 9, 10; IV, 5, 8; 6, 6-7, edición Vega, 1979) de Agustín de Hipona. También la misma civilización tiene un orden y finalidad divinamente señalados (Cv I, 11, 3; III, 15, 9; IV, $4,1)$. En todo este orden preestablecido en el ser humano y obrado por él, se descubre una particular gradualidad de la belleza: desde la belleza del cuerpo en el orden de sus miembros hasta la belleza del alma en el orden de las virtudes morales y en su labor de gobernar el cuerpo (Cv III, 15, 11; IV, 25, 11-12) (Tollemache, 1970; Sixdenier \& Tollemache, 1970).

Podríamos señalar otra fuente patrística al respecto. Con relación a los temas filosófico-teológicos del ordo y de la contemplatio, los estudios han evidenciado cada vez con más claridad la presencia del Pseudo-Dionisio Areopagita y de Boecio en Dante. De ambos autores ya hemos señalado varios aspectos. ${ }^{1}$

1 Hemos encontrado ya al Pseudo-Dionisio colocado en el IV Cielo del Sol, entre los espíritus sabios y los grandes doctores de la Iglesia, como quien más ha penetrado la naturaleza y servicio de los ángeles ( $\operatorname{Pr} \mathrm{X}, 115-117)$; y en la Ep XI, 7, junto con otros escritores cristianos, cuyas obras son recomendadas a los cardenales italianos.

Acerca de Boecio, ya hemos visto suficientes motivos: Dante lo coloca en el IV Cielo al interior de las dos grandes coronas de doce espíritus sabios, como modelo de vida y de doctrina sobre el bien (Pr X, 124-129); afirma haber leído su Consolatio philosophiae (Cv II, 12, 2; II, 15, 1), obra "«non conosciuto da molti" pero que fue para él una exhortación al cultivo de la filosofía entendida bajo la figura de una "donna gentile" y "misericordiosa"; además, Boecio es citado como exemplum de por qué y para qué hablar de sí mismo (Cv I, 2, 3-4.12-14) y como modelo de poesía filosófica. 
Dante no solo alaba las obras del Pseudo-Dionisio, sino que también las cita como autoridad (Jacomuzzi, 1986). Contamos explícitamente, en su Ep XIII, 21, con la mención del De coelesti hierarchia (III, 2, edición Martín, 2007) como autoridad acerca del principio según el cual virtudes e inteligencias son jerárquicamente dependientes de las inmediatamente superiores. Esta obra dionisiaca, según algunos estudios, en cuanto transmisora del principio neoplatónico — cristianizado en época patrística— según el cual la multiplicidad "procede" — cristianamente, por creación y participación — de la unidad con orden y jerarquías, parece inspirar la estructura de varias secciones de la Commedia.

Otros estudios, en cambio, se complacen en señalar más las diferencias, por ejemplo, entre ambos mundos, el dionisiaco y el dantesco. El primero está interesado solo en el orden espiritual en vista del regreso a la unidad divina, por lo que el simbolismo cumple la función de superar todo condicionamiento material por vía negativa. En el segundo, el orden cósmico está siempre relacionado con el orden espiritual en este regreso, por lo que su simbolismo es positivo y desarrolla con plasticidad las imágenes en sus condiciones materiales (Cristiani, 1970).

Con todo, lo repetimos, este autor desconocido permanece como autoridad en cuanto a la naturaleza, jerarquía y ministerio de los ángeles. Si, sobre este tema, en un primer momento, en Cv II, 5, Dante sigue a Gregorio Magno (Moralia in Iob XXXII, 48, edición Vogüé \& Adriaen, 2009; aunque diversamente expuesto en Homilia super Evangelia II, 14, 7-10, edición Gallardo \& Andrés, 1958), más adelante, reconoció en el PseudoDionisio (De coelesti hierarchia, edición Martín, 2007) mayor autoridad. Por ello, en Pr XXVIII, 98-139 señala su pensamiento, frente al cual Gregorio Magno ríe de sí mismo (Chiappelli \& Fenzi, 1986; Cornish, 2010; Franke 2010c; Gardner, 1968).

En verdad este detalle es muy conocido, a comparación de otras influencias del Pseudo-Dionisio a través de otros autores. En este caso la investigación va individuando ciertos aspectos al interior de la mística dantesca. Por ejemplo, se tiene el tema de los tipos de contemplatio según el Pseudo-Dionisio (De divinis nominibus IV, 8-10, edición Martín, 2007) a través del De contemplatione de Ricardo de San Víctor (Aris, 1996) y de la Summa Theologiae de Tomás de Aquino (II ${ }^{\mathrm{a}} \mathrm{II}^{\mathrm{ae}}$, qq. 179-189, edición Aniz, Colunga, García, \& Royo, 1950) presente en Pr XXI, 25.29-42 (Mocan, 2010: 189-198).

Respecto a Boecio, parece que la afinidad es mayor. Podemos sumar a lo ya visto una lista de las citas dantescas a la Consolatio boeciana (Pérez, 1997), con el fin de percibir en acto la valoración dantesca de la vida y pensamiento boecianos (Chiappelli \& Fenzi, 
1986; Took, 2010; Chiarenza, 2010; en particular, para una amplia y detallada exposición de cada uno de estos textos, revisar Lombardo, 2008, pp 134-503):

- en Mn I, 9, 3 cita la Consolatio (II, 8), al interior de la argumentación relativa a la Monarquía celeste reflejada en el imperio terreno, como un ideal político;

- en Mn II, 8, 13 cita la Consolatio (II, 6), acerca de la hegemonía del pueblo romano en la antigüedad;

- en Ep XIII, 33 cita la Consolatio (III, 9), como autoridad de la visión beatífica entendida como lo más alto que el hombre puede alcanzar;

- en Cv I, 11, 8 parafrasea la Consolatio (III, 6, 6), acerca del vacío de la gloria popular;

- en Cv II, 7, 4 cita la Consolatio (IV, 3, 11), sobre los sentidos dados a las palabras;

- en Cv II, 10, 3 cita la Consolatio (II, 1, 3), acerca del ánimo fluctuante;

- en Cv III, 1, 10 cita la Consolatio (II, 1, 10), acerca de la necesaria constancia sustancial que permanece en la apariencia y la providencia que en ello se muestra;

- en Cv III, 2, 17 cita la Consolatio (I, 4, 5), acerca del entendimiento humano;

- en Cv IV, 12, 7 cita la Consolatio (II, 2), acerca de la insaciable codicia humana;

- en Cv IV, 13, 13 cita la Consolatio (II, 5), sobre la avaricia;

- finalmente, como posibilidad, en If VII, 67-96 y Pr XVI, 82-84 y 142-147, la influencia temática del libro II de la Consolatio, acerca del tema de la fortuna y su interferencia en la vida humana.

El desarrollo dantesco del concepto del libre albedrío de la voluntad también se muestra dependiente de la especulación patrística, en especial de Boecio. En general, Dante desarrolla la relación entre la libertad humana y la predestinación y presciencia divinas. Por tanto, también expone la relación entre los méritos de la libertad humana creada y el premio proveniente de la libertad divina increada, debatiendo con quienes asumen ideas extremas, como la inutilidad de la oración o la negación de la presciencia divina (Pg XVI, 58-81.71-72; XVIII, 40-75; Pr V, 19-24; XVII, 37-42; Mn I, 12, 1-5).

Entre las fuentes de estos desarrollos suele citarse el libro V de la Consolatio y los Comentarii in Librum Aristotelis Peri Ermeneias boecianos (Tateo, 1970; Pérez, 1997; Meiser, 1877). Recordemos que en estos textos Boecio relee algunas tesis contenidas en las obras agustinas De libero arbitrio (Capánaga, 1982) y De correptione et gratia (Capánaga, 1956). En 


\section{GIANCARLO BELLINA SHOLS}

efecto, mientras que para Agustín la condición de posibilidad de la libertas humana se da en el liberum arbitrium voluntatis, para Boecio se da, ulteriormente, en el iudicium rationis (Botturi, 2006, pp. 6402-6403).

Pero lo cierto, en relación con Agustín de Hipona (Hawkins, 2010; Gardner, 1968; Pincherle, 1970), es que Dante desarrolló, a lo largo de toda su vida, una profunda asimilación de variados temas, tanto filosóficos como teológicos, a través de una continua lectio augustini. $\mathrm{Al}$ respecto, los estudios están a la orden del día. Ya hemos evidenciado varios aspectos. ${ }^{2}$ También hemos acotado su influencia en temas concretos. ${ }^{3}$ Además, las ediciones revisadas señalan a Agustín como fuente de otras concepciones dantescas:

- en Cv III,11, 4-6 se cita De civitate Dei (XVIII, 25, edición Morán, 1958) como fuente acerca de historiografía filosófica;

- $\quad$ en Cv IV, 5 y Mn II, 5 se cita De civitate Dei (V, 18, edición Morán, 1958) como fuente acerca del tema de la virtud de los personajes romanos;

- en VE I, 2, 6, la exegesis de Gn 3, 2-3 - la serpiente habla a la mujer - y Nm 22, 28-30 — la burra habla a Balaam — parece remontarse al De genesi ad litteram (XI, 27.29, edición Martín, 1957b);

- en VE I, 4, 6 y 7, 1-6 se cita como posibles fuentes De genesi ad litteram (III, 10; VIII, 27 y IX, 12; Martín, 1957b), Enarratio in Psalmo (148, 10-12; Pérez, 1953), De civitate Dei (XVI, 3-4.11.13; Morán 1958);

- VE I, 4, 2-7; 6, a1 parecer depende del De genesi ad litteram (VIII, 18; XI, 5.20, edición Martín, 1957b).

2 La influencia de doctrinas agustinas recibida a través de dos estudios florentinos, el agustino del Santo Spirito y el franciscano de la Santa Croce; Agustín es nombrado en $\operatorname{Pr}$ X, 120 y XXXII, 35, donde es colocado en la "Candida Rosa” al X Cielo; nombrado también en Mn III, 3, 14 y III, 4, 6-11, refiriéndose al De civitate Dei XVI, 2 y De doctrina christiana I, 36, y citando De doctrina christiana I, 37 acerca del senso mistico; nombrado en la Ep XI, 7, lamentándose del descuido en el cual se encuentran sus obras; referencia a las Confessiones (X, 3, 4) en Cv I, 2, 12-14, acerca de una razón válida para hablar de uno mismo; y referencia al De animae quantitate $(33,76)$ en la Ep XIII, 28 acerca de la contemplación.

3 Acerca de los cuatro sentidos al interpretar textos, el De utlitate credendi 3, 5-9; sobre la distinción agustina entre allegoria in verbis y la allegoria in facto del De Trinitate XV, 9, 15 (Arias, 1956), a la base de la distinción dantesca entre allegoria de li poeti y allegoria dei teologi; su influencia también en la relación fe-razón que Dante expone en muchas partes y que sigue de cerca el adagio agustino intellege ut credas, crede ut intelligas (Sermo 43, 9); influencia agustina en antropología (el hombre compuesto alma-cuerpo, valoración del cuerpo y sus bienes, necesidad de la ayuda de Dios para producir virtud y alcanzar la felicidad); influencia en la utilización de la categoría filosófica ordo a través del De animae quantitate y posiblemente del De ordine. 
Además, en las obras del Sumo Poeta encontramos elementos particulares de la teoría agustina del pecado y de la conversión, cristianizando algunos préstamos que se remontan al medio y al neoplatonismo. Acerca del pecado, Dante afirma que consiste en el "desprecio [y alejamiento] del uno-único [Dios] para progresar en los muchos [las creaturas] (progredi ad uno spreto ad multa)" (Mn I, 15, 3). Asimismo, agrega que es desorden o mal moral que proviene de la voluntad (Pg XVII, 85-102; 113-123) a causa del pecado original (Mn II, 12, 1-3) y que provoca una deformidad y desemejanza respecto a la original imagen de Dios en el hombre (Cv IV, 5, 3; Pr VII, 80).

En este mismo texto y en otros (Mn II, 12; Pr VII, 25-63) señala que la obra de riconformare la "umana creatura (...) partita e disformata" solo podía provenir de la inmensa bondad de Dios a través de la obra de su humilde y obediente Hijo. Desde la Commedia, la conversión consiste en "remover (removere) a los vivientes en esta vida del estado de miseria (statu miserie) y conducirlos (perducere) al estado de felicidad (statum felicitatis)" (Ep XIII, 15, edición Jacomuzzi, 1986, pp. 452-453), y prestar esta ayuda (Bufano, Delhaye \& Mellone, 1970; Meersseman, 1970; Socci, 2014).

Nótese a continuación las semejanzas de lo anterior con el pensamiento agustino. Agustín presenta un concepto de pecado en relación con los conceptos de aversión y multiplicidad. El santo lo denomina "aversión del bien inmutable y conversión a los bienes mudables (aversio eius ab incommutabili bono et conversio ad mutabilia bona)" (De libero arbitrio II, 19, 53, edición Capánaga, 1982; De diversis quaestionibus ad simplicianum I, 2, 18, edición Capánaga, 1952a), desprecio (en cuanto amor torcido y desordenado, según la definición de las dos ciudades, De civitate Dei XIV, 28, edición Morán, 1958), dispersión, desemejanza (Confessiones VII, 10, 16; XIII, 2, 2-3, edición Vega, 1979), acto “in nostra potestate" (De libero arbitrio III, 3, 8, edición Capánaga, 1982), o sea, voluntario, por lo que "le sigue de cerca la digna y justa pena de la infelicidad ("digna est iusta eam miseriae poena subsequitur)” (De libero arbitrio II, 19, 53, edición Capánaga, 1982).

El camino de conversión, comenzando en la interioridad (volver a sí mismo), llega a la trascendencia (a Dios) pasando por la reformatio-religatio. Es decir, pasa por la acogida de la gracia de Dios a través de la redención de Cristo Humilde. Esto se puede constatar en Confessiones (VII, 14, 20-21, 27, edición Vega, 1979) y en De animae quantiate (28, 55; 33, 70-34, 78, edición Cuevas, 1963). 


\subsubsection{Politica}

Pues bien, esta doctrina antropológica está a la base de las concepciones acerca del providencial orden político que Dante expone en Mn III, 15, 10-18. Previamente, el poeta ha señalado que las diversas felicidades temporal y eterna, antes descritas, suponen necesariamente "medios diversos (diversa media)" para conseguirlas: el hombre cuenta, por un lado, en vista de la felicidad temporal, con las "enseñanzas filosóficas (documenta phylosophica)", fruto de la razón humana que le señalan la vida ordenada según las virtudes morales e intelectuales; por otro lado, cuenta con las «enseñanzas espirituales que trascienden la razón humana (documenta spiritualia que humanam rationem trascendunt)", reveladas por el Espíritu Santo, que le señalan las virtudes teologales en vista de la felicidad eterna (Mn III, 15, 8-9, edición Gaia 1986, pp. 772-775).

Con todo, la providencia divina socorre, aquí en la tierra, la situación humana de desorden moral (deseos de poder y de tener) y de profunda búsqueda de ambas felicidades, la temporal y la eterna, $y$, a modo de remedio que refrena los deseos desordenados y conduce a los hombres por la recta vía, le otorga una "doble guía (duplex directivum)". Esta, a saber, se trata de dos instituciones históricas preestablecidas para ser medios que brinden sus servicios al hombre: el Emperador y el Sumo Pontífice. El primero es autoridad política que conduce a la felicidad terrena a través de la filosofía y salvaguardando una situación común de libertad y paz; el segundo es autoridad espiritual que conduce a la vida eterna a través de la teología; ambas guías provienen de Dios "sin intermediarios (sine ullo medio)" (Mn III, 15, 10-15, edición Gaia, 1986, pp. 775-777).

La primera, llamada monarquía temporal o imperio, queda justificada en las obras de Dante a través de una interpretación religiosa y escatológica de la historia romana, desde una vertiente cristiana que asume elementos de la metafísica neoplatónica y de la ética y política aristotélicas. Nuestro autor afirma que Dios, quien dirige los destinos con sabiduría, ha demostrado su preferencia por este tipo de gobierno temporal. En concreto, en Cv IV, 5 , 4-10 señala la doble feliz coincidencia, preparada por Dios, entre el nacimiento de David y de Roma, y entre la venida de Cristo y el mejor momento del imperio romano, ambos como signo de la misión de restaurar la concordia entre Dios y los hombres.

En efecto, en este texto, nuestro autor insiste en que no hay mejor "disposizione de la terra" sino bajo una monarquía, es decir, "tutta ad uno principe (...) a la voce d'un solo principe, di Roma" (Cv IV, 5, 4-8, edición Chiappelli \& Fenzi, 1986, pp. 226-227), lo que 
se confirma con el fruto de la pax romana. Dante continúa con una presentación del pueblo romano como heroico y virtuoso (también presente en Mn II, 5) dependiente de Agustín de Hipona (De civitate Dei V, 18, edición Morán, 1958). En otros textos expone la elección divina de Roma como sede del imperio (If II, 13-24) y la paz universal querida por Dios al momento del nacimiento de Cristo (Pr VI, 34-90; VII, 94-120; Mn I, 16).

Esta lectura providencialista de hechos históricos surgió junto con la historiografía cristiana en la antigüedad tardía, por lo que es posible percibir ecos patrísticos en ella. En efecto, obispos como Eusebio de Cesarea en su Historia Ecclesiastica (también, por ejemplo, la Apología perdida ahí citada, que contenía como argumento la feliz coincidencia histórica del adviento de Cristo con la paz de Augusto - a saber, la Apología de Melitón de Sardes (IV, 26, 7-8, edición Velasco-Delgado, 2008, pp. 255-256)-) y en su Vita Constantini (Gurruchaga 1994), obras conocidas por Dante posiblemente a través del tomo Speculum Historiale de la obra enciclopédica Speculum maius del dominico Vicente de Beauvais (Beauvais, 1591), León Magno (Sermo 82, 2; edición León Magno, 2013) o Gregorio Magno (Epistula XI, 37, edición Recchia, 1999) la sostuvieron para incentivar las relaciones entre gobernadores cristianos y obispos. Para otras fuentes patrísticas ver Gaia, 1986, p. 587, nota 14 .

Con todo, el movimiento de la argumentatio dantesca es propio. Ya en Cv IV, 4 se exponen los elementos que sustentan la necesidad de que la civilización humana esté ordenada "a uno fine" y guiada por "uno solo principato e uno prencipe", para conseguir la paz y la libertad. Todo esto se presenta en estrecha relación con el tratado Política de Aristóteles (García 1988).

Lo que sí coincide es el argumento que asume una jerarquía entre ambos poderes. Así, en Mn III, 15, 16-18 llega a afirmar que las conclusiones sobre la separación entre los dos poderes no deben entenderse en sentido muy estricto, pues el emperador es de alguna manera inferior al Papa, en cuanto la "felicidad mortal (mortalis felicitas) de alguna manera está ordenada (ordinetur) hacia la felicidad inmortal (ad inmortalem felicitatem)" (Mn III, 15, 17, edición Gaia, 1986, pp. 778-779). De esta manera, el César debe tener reverentia por Pedro, como un primogénito hacia su padre. Con todo, para Dante reverencia no implica la subalternancia o dependencia de la autoridad mundana respecto a la espiritual (Vasoli, 2006; Franke 2010b; Bertelloni, 2008).

La segunda monarquía, al mando del Sumo Pontífice, se encuentra al interior de la Iglesia. Así la presenta cuando en If (XV, 112ss.) describe la "forma de la Iglesia" como 
la humilde vida humana de Cristo lejana de todo poder temporal y al servicio del anuncio del Reino de Dios y de la preparación de su segunda venida. Además, afirma que el Papa es quien, como Pedro, acepta la invitación de Cristo a imitarle de cerca, hasta ser considerado «servo di'servi».

Es sabido que esta última expresión fue acuñada en época patrística. En efecto, se trata de una expresión de relación que reúne los ideales evangélicos de humildad y servicio al otro, característicos del buen pastor, Jesús, asumidos con mentalidad cenobítica y luego desde su función episcopal, basada en el uso apostólico de servus (Rm 1, 1; Flp 1, 1; 2, 5-11; Tt 1, 1; 1 P 1, 1; St 1, 1; Judas 1). Esta fue usada por el Papa Dámaso (Epistula 4, edición Mansi, 1759, col. 431), por Agustín de Hipona (Epistulae 130 y 217, edición Cilleruelo, 1953; De peccatorum meritis et remissione et de baptismo parvulorum III, 1, edición Capánaga, 1952b), y ampliamente por Gregorio Magno (Epistulae VI, 52; XI, 39.45.56, entre otras, edición Recchia 1996 y 1999).

\section{Conclusión}

$\mathrm{H}$

emos podido evidenciar una variedad de contenidos literarios, filosóficos y teológicos, originalmente patrísticos, relativos a temas importantes como la concepción de la alegoría, del hombre, de la política, de la Iglesia, presentes en Dante y acogidos de manera directa o indirecta. En el sumo poeta estos contenidos se asimilan y reutilizan en una síntesis propia asumiendo direcciones diversas a los originales. La ejemplaridad de esta acogida resulta evidente, en cuanto no se trató de una actividad intelectual de evasión o de mera repetición de contenidos, sino de una elaboración de contenidos al servicio de necesidades concretas, como la de vulgarizar la filosofía o promover la reforma eclesial.

De esta manera, los textos patrísticos, en el escritorio de Dante, cobraron actualidad y sirvieron para transmitir cultura, espiritualidad, reforma eclesial, inspiración poética y contenidos filosóficos. Esto mismo se vive en muchos lugares del mundo hoy, demostrando que tanto Dante como los Padres de la Iglesia fecundan eficazmente la vida intelectual y moral de un pueblo. Y, respecto a quien dude de esto, podríamos responder con la expresión dantesca respecto a los Padres: "o nunca ha visto sus frutos, o, si los ha visto, nunca los ha gustado” (Mn III, 3, 14, edición Gaia, 1986, pp. 700-701). 


\section{Referencias}

Abascal, S. (Ed.). (1982). Santo Tomás de Aquino. Comentario A los Gálatas. México D.F., México: Tradición.

Agustino. (Ed.). (1956). Obras de San Agustín en edición bilingüe. Tomo IV. Obras apologéticas. De la utilidad de creer (pp. 821-899). Madrid, España: B.A.C.

Aniz, C., Colunga, A., García Álvarez, J., \& Royo, A. (Eds.). (1950). Santo Tomás de Aquino. Suma teológica X [2-2 qq. 141-189]. Madrid, España: B.A.C.

Arias, L. (Ed.). (1956). Obras de San Agustín en Edición bilingüe. Tomo V. Tratado sobre la Santísima Trinidad. Madrid, España: B.A.C.

Aris, M.-A. (Ed.). (1996). Richard von St. Victor. De contemplatione. En Contemplatio. Philosophische Studien zum Traktat Benjamin Maior des Richard von St. Victor: mit einer verbesserten Edition des Textes (pp. 3-148). Frankfurt, Alemania: J. Knecht.

Barbieri, G, Cecchin, S., Jacomuzzi, A., \& Stassi, M. G. (Eds.). (1983). Opere Minori di Dante Alighieri. Volume primo. Vita Nuova, De vulgari eloquentia, Rime, Ecloge. Torino, Italia: U.T.E.T.

Beauvais, V. de. (1591). Speculi Maioris Vincentii Burgundi. Tomus Quartus. Qui Speculum Historiale Inscribitur. Venezia, Italia: Apud Dominicum Nicolinum.

Bertellonni, F. (2008). Introducción. La vida y el periplo intelectual de Dante (Trad. M. Pérez Carrasco). En Dante Alighieri. Convivio (pp. 5-71). Buenos Aires, Argentina: Calihue. 
Botturi, F. (2006). Libertà. En Enciclopedia Filosofica Bompiani. Lan - Mem. (Vol. 7, pp. 6393-6450). Milano, Italia: Bompiani.

Bufano, A., Delhaye, Ph., \& Mellone, A. (1970). Peccato. En Enciclopedia Dantesca. (Vol. IV). Roma, Italia: Istituto dell'Enciclopedia Italiana. Recuperado de http://www.treccani.it/enciclopedia/peccato_(Enciclopedia-Dantesca)/

Brunetti, G., \& Gentili, S. (2000). Una biblioteca nella Firenze di Dante: i manoscritti di Santa Croce. En E. Russo (Ed.), Testimoni del vero. Su alcuni libri in biblioteche di autore (pp. 21-55). Roma, Italia: Bulzoni.

Capánaga, V. (Ed.). (1952a). Obras de San Agustín en edición bilingüe. Tomo IX. Tratados

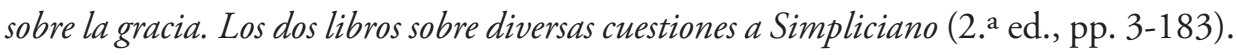
Madrid, España: B.A.C.

Capánaga, V. (Ed.). (1952b). Obras de San Agustín en edición bilingüe. Tomo IX. Tratados sobre la gracia. De los méritos y perdón de los pecados (2. a ed., pp. 187-453). Madrid, España: B.A.C.

Capánaga, V. (Ed.). (1956). Obras de San Agustín en edición bilingüe. Tomo VI. Tratados sobre la gracia. De la corrección y de la gracia (pp. 121-221). Madrid, España: B.A.C.

Capánaga, V. (Ed.). (1969). Obras de San Agustín en edición bilingüe. Tomo I. Del orden (pp. 589-707). Madrid, España: B.A.C.

Capánaga, V. (Ed.). (1982). Obras de San Agustín. Edición bilingüe. Tomo III. Obras filosóficas. El libre albedrio (pp. 193-432). Madrid, España: B.A.C.

Chiappelli, F., \& Fenzi, E. (Eds.). (1986). Il Convivio. En Opere Minori di Dante Alighieri (Vol. 3, pp. 9-322). Torino, Italia: U.T.E.T.

Chiarenza, M. (2010). Boethius. En R. Lansing (Ed.), The Dante Encyclopedia (pp. 118119). New York, Estados Unidos: Routledge. 
Chimenz, S. A. (1960). Alighieri, Dante. En Dizionario Biografico degli Italiani. (Vol. 2, pp. 385-451). Roma, Italia: Istituto della Enciclopedia Italiana. Recuperado de http:// www.treccani.it/enciclopedia/dante-alighieri_(Dizionario-Biografico)/

Chimenz, S. A. (Ed.). (2003). La Divina Commedia di Dante Alighieri. Torino, Italia: U.T.E.T.

Cilleruelo, L. (Ed.). (1953). Obras de San Agustín en edición bilingüe. Tomo XI. Cartas (2. ${ }^{\text {a }}$ ed.). Madrid, España: B.A.C.

Cipriani, N. (junio, 2007). Il tema agostiniano dell'actio-contemplatio nel suo quadro antropologico. En Augustinianum 47(1), 145-169.

Cornish, A. (2010). Angels. En R. Lansing (Ed.), The Dante Encyclopedia (pp. 37-45). New York, Estados Unidos: Routledge.

Cristiani, M. (1970). Dionigi l'Areopagita. En Enciclopedia Dantesca (Vol. 1, pp. 460-463). Roma, Italia: Istituto dell'Enciclopedia Italiana. Recuperado de http://www.treccani.it/enciclopedia/dionigi-l-areopagita_(Enciclopedia-Dantesca)/

Crouse, R. (2008). Padri nel Medioevo. En A. Di Berardino (Dir.), Nuovo Dizionario Patristico e di Antichità Cristiana - P-Z (2. ${ }^{a}$ ed., pp. 3729-3737). Milano, Italia: Marietti.

Cuevas, E. (Ed.). (1963). Obras de San Agustín en edición bilingüe. Tomo III. De la cuantidad del alma (pp. 412-523). Madrid, España: B.A.C.

Davis, Ch. (1988). The Florentine Studia and Dante's "Library". En G. Di Scipio \& A. Scaglione (Eds.), The Divine Comedy and the Encyclopedia of Arts and Sciences (pp. 339-366). Amsterdam, Holanda: John Benjamins Publishing Company.

Davis, Ch. (1986). Scuola. La scuola a tempo di Dante. En Enciclopedia Dantesca. (Vol. 5; pp. 106-108). Roma, Italia: Istituto dell'Enciclopedia Italiana. Recuperado de http://www.treccani.it/enciclopedia/scuola_(Enciclopedia-Dantesca)/ 
DelCogliano, M. (Ed.). (2012). Gregory the Great. On The Song of songs. Minnesota, Estados Unidos: Cistercian Publications.

Donati, S., Punta, F. del, \& Luna, C. (1993). Egidio Romano. En Dizionario Biografico degli Italiani. (Vol. 42). Roma, Italia: Istituto della Enciclopedia Italiana. Recuperado de http://www.treccani.it/enciclopedia/egidio-romano_(Dizionario_Biografico)/

Durling, R. M. (2010). Body, Human. En R. Lansing (Ed.), The Dante Encyclopedia (pp. 115-118). New York, Estados Unidos: Routledge.

Franke, W. (2010a). Albert the Great. En R. Lansing (Ed.), The Dante Encyclopedia (p. 11). New York, Estados Unidos: Routledge.

Franke, W. (2010b). Constantine. En R. Lansing (Ed.), The Dante Encyclopedia (pp. 216 217). New York, Estados Unidos: Routledge.

Franke, W. (2010c). Dionysius the Areopagite. En R. Lansing (Ed.), The Dante Encyclopedia (pp. 304-305). New York, Estados Unidos: Routledge.

Gaia, P. (Ed.). (1986). Monarchia. En Opere Minori di Dante Alighieri (Vol. 3, pp. 471781). Torino, Italia: U.T.E.T.

Gallardo, P., \& Andrés, M. (Eds.) (1958). Obras de San Gregorio Magno. Regla Pastoral. Homilias sobre la profecía de Ezequiel. Cuarenta homilías sobre los Evangelios. Madrid, España: B.A.C.

García, M. (Ed.). (1988). Aristóteles. Politica. Madrid, España: Gredos.

Gardner, E. G. (1968). Dante and the Mystics. A study of the mystical aspect of the Divina Commedia and its relations with some of its Medieval Sources. New York, Estados Unidos: Octagon Books.

Gauthier, R.-A. (Ed.). (1996). Sancti Thomae de Aquino doctoris angelici Opera Omnia. Quaestiones de quolibet. Roma, Italia: Commissio Leonina-Cerf. 
Ghisalberti, A. (1996). Capitolo Quinto. Dante Alighieri: la teologia del poeta. En G. D’Onofrio (Dir.), Storia della Teologia nel Medioevo. III La teologia delle scuole (pp. 301-323). Casale Monferrato, Italia: Piemme.

Guillet, R., \& Gaudemaris, A. (Eds.). (1950). Grégoire le Grand. Morales sur Job. Livres 1 et 2. París, Francia: Cerf.

Gurruchaga, M. (Ed.). (1994). Eusebio de Cesarea. Vida de Constantino. Madrid, España: Gredos.

Havely, N. (2010). Poverty. En R. Lansing, (Ed.), The Dante Encyclopedia (pp. 705-707). New York, Estados Unidos: Routledge.

Hawkins, P. S. (2010). Augustine, St. En R. Lansing (Ed.), The Dante Encyclopedia (pp. 71 72). New York, Estados Unidos: Routledge.

Jacomuzzi, A. (Ed.). (1986). Epistole. En Opere Minori di Dante Alighieri (Vol. 3, pp. 323469). Torino, Italia: U.T.E.T.

Landoni, E. (2014). Orper empierti bene ogne disio. Lingua e letteratura, fede e ragione, amore e libertà in Dante. Mantova, Italia: Unversitas Studiorum.

León Magno. (2013). Omelie e lettere. Torino, Italia: U.T.E.T.

Lledó, E., \& Palli, J. (Eds.). (1985). Aristóteles. Ética Nocomáquea. Ética Eudemia. Madrid, España: Gredos.

Lombardo, L. (2008). Boezio in Dante. La Consolatio philosophiae nello scrittoio del poeta. Tesi di dottorato. Venezia, Italia: Università Ca’ Foscari. Recuperado de http://dspace.unive.it/bitstream/id/832/license.txt/

Lubac, H. de. (1972). Esegesi Medievale. I quattro sensi della Scrittura. Roma, Italia: Ed. Paoline. 
Mansi, J. D. et successores. (1759). Sacrorum Conciliorum Nova Et Amplissima Collectio. Editio Novissima. Tomus Tertius. Ab anno CCCXLVII. ad annum CCCCIX. Florencia, Italia: Antonium Zatta.

Martín, B. (Ed.). (1957a). Obras de San Agustín en edición bilingüe. Tomo XV. De la doctrina cristiana (pp. 49-349). Madrid, España: B.A.C.

Martín, B. (Ed.). (1957b). Obras de San Agustín en edición bilingüe. Tomo XV. Del Génesis a la letra (pp. 567-1271). Madrid, España: B.A.C.

Martín, T. H. (Ed.). (2007). Pseudo Dionisio Areopagita. Obras Completas. Madrid, España: B.A.C.

Martínez, R. A. (2010). Allegory. En R. Lansing (Ed.), The Dante Encyclopedia (pp. 24-34). New York, Estados Unidos: Routledge.

Mazzotta, G. (2010). Alighieri, Dante. En R. Lansing (Ed.), The Dante Encyclopedia (pp. 15-20). New York, Estados Unidos: Routledge.

Meersseman, G. G. (1970). Conversione. En Enciclopedia Dantesca (Vol. 2). Recuperado de http://www.treccani.it/enciclopedia/conversione_(Enciclopedia-Dantesca)/

Meiser, C. (Ed.). (1877). Anicii Manlii Severini Boetii Commentarii in librum Aristotelis Peri ermeneias. Leipzig, Alemania: Teubner.

Micunco, G. (Ed.). (2007). Laelius De Amicitia. Lelio L'amicizia. En Opere Politiche e filosofiche di M. Tullio Cicerone (pp. 517-607). Torino, Italia: U.T.E.T.

Mocan, M. (2010). In avibus intellige spiritualia. Sulle fonti di Paradiso XXI, 34-42. En C. Bologna, M. Mocan \& P. Vaciago (Eds.), Percepta Rependere Dona. Studi di filologia per Anna Maria Luiselli Fadda (pp. 189-205). Firenze, Italia: Leo S. Olschki Editore.

Morán, J. (Ed.). (1958). Obras de San Agustín. Edición bilingüe. Tomos XVI y XVII. La Ciudad de Dios. Madrid, España: B.A.C. 
Pérez, B. M. (Ed.). (1953). Obras de San Agustín en edición bilingüe. Tomo XXII. Enarraciones sobre los Salmos (4. ${ }^{\mathrm{a}}$ ed.). Madrid, España: B.A.C.

Pérez, L. (Ed.). (1997). Boecio. La consolación de la filosofía. Madrid, España: Akal.

Pérez, M. (2012). Hacia una filosofía de la lengua vulgar. Filosofía, poesías y traducción en el Convivio dantesco. Scientia Traductionis, 11, 207-227.

Perotto, L. (Ed.). (1998). Commento all'Etica Nicomachea di Aristotele (Sententia Libri Ethicorum). Vol. I, libri I-V. Bologna, Italia: EDB.

Pincherle, A. (1970). Agostino Aurelio di'Ippona, santo. En Enciclopedia Dantesca (Vol. 1, pp. 80-82). Recuperado de http://www.treccani.it/enciclopedia/agostino-aurelio-dippona-santo_(Enciclopedia_Dantesca)/

Recchia, V. (Ed.). (1996). Opere di Gregorio Magno V/2 Lettere (IV-VII). Roma, Italia: Città Nuova.

Recchia, V. (Ed.). (1999). Opere di Gregorio Magno VI4 Lettere (XI-XIV, Appendici). Indici. Roma, Italia: Città Nuova.

Sasso, L. (1995). Trattatello in laude di Dante di Giovanni Boccaccio. Milano, Italia: Garzanti.

Sixdenier, G. D., \& Tollemache, F. (1970). Ordine. En Enciclopedia Dantesca (Vol. 4). Recuperado de http://www.treccani.it/enciclopedia/ordine_(EnciclopediaDantesca)/

Socci, L. (2014). Dante e Agostino: cor ad cor loquitur. Recuperado de https://www.academia. edu/19251787/Dante_e_Agostino_cor_ad_cor_loquitur

Stephany, W. (2010). Soul. En R. Lansing (Ed.), The Dante Encyclopedia (pp. 795-797). New York, Estados Unidos: Routledge.

Suárez, R., \& Muñiz, F. (Eds.). (1947). Santo Tomás de Aquino. Suma teológica I l1 qq. 1-26]. Madrid, Espańa: BAC Normal. 
Tateo, F. (1970). Boezio, Severino. En Enciclopedia Dantesca (Vol. 1, pp. 654-658). Recuperado de http://www.treccani.it/enciclopedia/severino-boezio_(EnciclopediaDantesca)/

Teuber, B. (2009). Alegoría de los teólogos, alegoría de los poetas: Prudencio, Dante, Lezama Lima. En J. Barja \& J. Pérez de Tudela (Eds.), Dante. La obra total (pp. 303350). Madrid, España: Círculo de Bellas Artes.

Tollemache, F. (1970). Ordinare. En Enciclopedia Dantesca (Vol. 4). Recuperado de http://www.treccani.it/enciclopedia/ordinare_(Enciclopedia_Dantesca)/

Took, J. (2010). Lady Philosophy. En R. Lansing (Ed.), The Dante Encyclopedia (pp. 551553). New York, Estados Unidos: Routledge.

Truijen, V. (1970). Fede. En Enciclopedia Dantesca (Vol. 2, pp. 820-822). Recuperado de http://www.treccani.it/enciclopedia/fede_(Enciclopedia-Dantesca)/

Vasoli, C. (2006). Dante Alighieri. En Enciclopedia Filosofica Bompiani. Col - Dol (Vol. 3, pp. 2520-2532). Milano, Italia: Bompiani.

Vega, Á. C. (Ed.). (1979). Obras de San Agustín. Texto bilingüe. Tomo II. Las Confesiones. Madrid, España: B.A.C.

Velasco-Delgado, A. (Ed.). (2008). Eusebio de Cesarea. Historia Eclesiástica. Texto bilingüe. Madrid, España: B.A.C.

Vogüé, A. de., \& Adriaen, M. (Eds.). (2009). Grégoire le Grand. Morales sur Job. Livres 3032. París, Francia: Cerf. 